\title{
In Vitro Activities of Fluoroquinolones Entrapped in Non-ionic Surfactant Vesicles against Ciprofloxacin-Resistant Bacteria Strains
}

\author{
Jankie Satish ${ }^{1}$, Adebayo S. Amusa ${ }^{2 *}$ and Pillai Gopalakrishna ${ }^{3}$
}

\begin{abstract}
Background: Recent findings suggest bacteria's ability to adapt to various classes of antibiotics through three distinct resistance mechanisms: lipopolysaccharide modification, increased drug efflux, and reduced porin pathway. These mechanisms involve the adaptive response by bacteria to specific signal due to antibacterial presence in its environment, leading to up- and down regulation of the efflux system (MexXY/OprM), and the porin pathway (OprD) respectively. Molecular encapsulation in niosomes could block signal generation and prevent bacteria from recognizing the presence of encapsulated drug molecules, enhance fusogenic properties and enable drug assimilation.

Methods: Niosomes of select fluoroquinolones (i.e. ciprofloxacin, gatifloxacin, levofloxacin and norfloxacin) were prepared using thin film rehydration method and the parameters controlling niosomal drug loading were investigated including the speed of evaporation, temperature of rehydration, time of rehydration and volume of rehydration, using percent (\%) drug loading as output variable. In vitro activity of noisome encapsulated fluoroquinolones against twenty ciprofloxacinresistant bacteria strains (each of Pseudomonas aeruginosa, Escherichia coli and Staphylococcus aureus) was determined by broth microdilution technique. Paired sample t-test was performed for independent sample comparison while multi-group analysis was done with one-way analysis of variance (ANOVA) and significance determined at $95 \%$ confidence level using MINITAB 16 statistical package.

Results: Entrapment efficiencies for the fluoroquinolones were $71.11 \pm 1.39 \%$ (ciprofloxacin), $19.11 \pm 1.86 \%$ (gatifloxacin), $34.23 \pm 1.86 \%$ (levofloxacin) and $70.09 \pm 1.64 \%$ (norfloxacin) respectively. The formulations displayed temperature-dependent stability with the highest stability occurring at $5^{\circ} \mathrm{C}$ and the lowest at $37^{\circ} \mathrm{C}$ respectively. Drug diffusion across dialyzing membrane was slower from the vesicles and followed a more sustained profile compared with the non-encapsulated drug particles. Analysis of drug liberation kinetics suggests first-order (concentration-dependent) release from the vesicles.

Conclusions: The niosomes of fluoroquinolones produced at least two-fold reduction in MIC's against Pseudomonas aeruginosa and Escherichia coli, and at least four-fold reduction in MIC's against Staphylococcus aureus. Results therefore suggest the potential for enhancement of fluoroquinolones delivery to their target sites in the bacteria cytoplasm through formulation in niosomes.
\end{abstract}

Key words: fluoroquinolones, niosomes, drug delivery, in vitro antibacterial activity

\section{Introduction}

Fluoroquinolones are potent broad-spectrum antibiotics which show excellent in-vitro activity against members of the family Enterobacteriaceae (e.g. Escherichia coli and Pseudomonas aeruginosa), non-Enterobacteriaceae gram-negative, grampositive (e.g. Staphylococcus aureus), anaerobic and other types of bacteria [1]. After absorption, fluoroquinolones are extensively distributed and tissue concentrations often exceed serum levels [2-4]. This renders the drugs particularly useful for treating a wide variety of infections, such as gonococcal, osteomyelitis and

*correspondence: aadebayo02@roosevelt.edu

2Department of Biopharmaceutical Sciences, College of Pharmacy, Roosevelt University, Chicago/Schaumburg, IL 60173, USA.

Full list of Author information is available at the end of the article respiratory tract infections, and as prophylaxis in neutropenic and post-surgical conditions [2].

Their tissue penetrating ability is superior to other antibiotics [3-5] with accumulation in the macrophages [5] and neutrophils [6]. Fluoroquinolones have been considered the drugs of choice for treating clinical diseases caused by intracellular pathogens. Availability in oral dosage forms make them suitable for use in both clinical and community settings. This, however, has enhanced their selection pressure, made them targets for misuse and predisposed them to resistance development with loss of activity against various bacteria [7].

The main mechanisms by which bacteria develop resistance to antimicrobial agents have been identified as enzymatic drug inactivation, alteration of target site, reduced cellular uptake and increased efflux [8-10]. Topoisomerases, the

(c) 2012 Adebayo et al; licensee Herbert Publications Ltd. This is an open access article distributed under the terms of Creative Commons Attribution License (http://creativecommons.org/licenses/by/3.0), This permits unrestricted use, distribution, and reproduction in any medium, provided the original work is properly cited 
target enzymes for fluoroquinolones, are located in the bacteria cytoplasm and changes in permeability of the outer membrane of gram-negative bacteria cell has been linked with resistance development. In addition, several multidrug efflux transporters belonging to the Multidrug and Toxin Extrusion (MATE) family have been identified [8] including NorM of Vibrio parahaemolyticus, a protein with 12 transmembrane helices which pumps out fluoroquinolones and ethidium in exchange for the influx of $\mathrm{Na}+[9,10]$. Muller, Plésiat and Jeannot [11] reported the role of a two-component signal transduction system (ParRS) in bacterial adaptation to some antibiotics, including fluoroquinolones, through three distinct resistance mechanisms: LPS modification, increased drug efflux, and a reduced porin pathway. Therefore, devising mechanisms for enhanced delivery of fluoroquinolones and other antibacterial agents through the bacteria wall may significantly improve the sensitivity of the cells to these agents.

Recent reports in the literature indicate the feasibility of enhancing antimicrobial drug uptake by vesicular encapsulation. Studies have shown that the distribution and localization of colloidal carriers in tissues, cellular and sub-cellular areas parallel distribution into the common bacteria cells that are responsible for intracellular infections [2]. Liposome encapsulated ciprofloxacin showed superior therapeutic efficacy against Francisella tularensis infection in mice [12] while ofloxacin loaded liposomes yielded MICs which were at least half of those obtained with the free drug when tested against Enterococcus faecalis, Escherichia coli, Staphylococcus aureus and Pseudomonas aeruginosa [13]. However, liposomes are expensive, chemically unstable (prone to oxidative degradation) and the purity of natural phospholipids used in their construction is highly variable $[14,15]$.

Niosomes are microscopic lamellar structures formed from admixture of non-ionic surfactant and cholesterol with subsequent hydration in an aqueous medium. They have the ability to accommodate drug molecules with a wide range of solubility. In addition, niosomes are osmotically active and stable, have the potential to increase the metabolic stability and prolong in vivo circulation of entrapped drug. The surfactants used for its construction are biodegradable, biocompatible and non-immunogenic. Niosomes behave in vivo like liposomes, but the formulations tend to be more stable, less toxic and less immunogenic $[14,15]$.

This study was designed to investigate the effect of niosomes encapsulation on the delivery of select fluoroquinolones into bacterial cells using the MIC measurements, characterize the vesicles and determine the effect of storage temperature on their stability.

\section{Materials and methods Materials}

Ciprofloxacin, levofloxacin and norfloxacin were products of Bayer Vital (Wuppertal, Germany) while Gatifloxacin was a product of Pfizer (Karlsruhe, Germany). Cholesterol, dicetyl phosphate and Span 60 were purchased from Sigma Chemicals (Canada). All solvents used were of the high performance liquid chromatography (HPLC) grade while all other chemicals were of analytical grade.

\section{Sample collection}

Bacterial samples were collected from the Microbiology Department of the Eric Williams Medical Sciences Complex, Trinidad and Tobago, West Indies. The organisms were obtained from patients on admission at the hospital with various types of infections. The causative organisms were isolated and their susceptibility patterns determined using microscan (Dade Behring Microscan Inc, CA). Sixty (60) ciprofloxacin-resistant isolates (20 each) of E. coli, P. aeruginosa and S. aureus, were collected. They were cultured onto blood agar plates and pure colonies were stored on nutrient agar slants at $4{ }^{\circ} \mathrm{C}$.

\section{Preparation of vesicles}

Vesicles were prepared using the thin film hydration method. The surfactant (span 60), cholesterol and dicetyl-phosphate in the molar ratio of 47.5:47.5:5.0 were dissolved in chloroform. The antimicrobial agents, ciprofloxacin, gatifloxacin, levofloxacin and norfloxacin respectively, were also dispersed (or dissolved depending on lipophilicity) in chloroform with mixing (Vortex Genie, Scientific Ind. Inc, NY). The surfactant solution and drug dispersion/solution were mixed on vortex mixer for 10 minutes and then sonicated for $15 \mathrm{~min}$. The sample was then evaporated in a rotary flash evaporator (Buchi rotavapor R-200/ water bath B-450, Büchi Labortechnik AG) under reduced pressure to obtain a thin and uniform film deposited in the inner wall of the flask. The thin film was then re-hydrated with phosphate buffer saline ( $\mathrm{pH}$ 7.4).

\section{Determination of the quantity of drug encapsulated}

The samples of the resulting vesicles were subjected to ultracentrifugation for one (1) hour at $20,000 \mathrm{rpm}$ at $5^{\circ} \mathrm{C}$. After the first cycle, the supernatant was removed and the contents of the vial re-suspended in phosphate buffer saline and spun again at 20,000 rpm for one (1) hour. This procedure was repeated three (3) times. The supernatant solutions were combined and the drug content was determined by UV-VIS spectrophotometry at the wavelength of maximum absorption of the respective fluoroquinolone ( $283 \mathrm{~nm}, 292 \mathrm{~nm}, 288 \mathrm{~nm}$ and $272 \mathrm{~nm}$ respectively for ciprofloxacin, gatifloxacin, levofloxacin norfloxacin). The amount of drug encapsulated was calculated

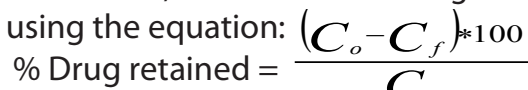

Where $C_{0}$ is the initial amount of fluoroquinolone used and $C_{f}$ is the amount of non-encapsulated drug removed by centrifugation.

\section{Size analysis}

The dispersion unit of the Mastersizer 2000 was cleaned twice 
with Phosphate Buffer Saline (PBS) prior to each measurement. The chamber was carefully loaded with dispersant (PBS) until no air space and bubbles can be seen from the outside glass of the chamber. The chamber was put in place and allowed to stir. Sample was shaken well and introduced drop-wise into the dispersion chamber with plastic pipette until a nice single peak distribution was obtained on the computer monitor. The instrument was allowed to stir and measure for further 2 minutes before the reading was taken (In case of persistent multiple peaks, appearance post 2 minute was sought and another waiting time of 2 minutes was allowed before taking the final reading). Data was reported as volume distribution.

\section{Electron Microscopy}

The electron microscopy (EM) of the niosomes was performed using negative staining technique. Thick samples were diluted four times (in volume) with filtered PBS dispersant. Droplets of the niosomes sample were mixed in equal volume with aqueous $1 \%$ uranyl acetate on a specimen support grid and immediately dried down using filter paper. The negative stained samples were then imaged under TEM.

\section{Stability of vesicles}

Samples of vesicles containing known quantities of each drug were prepared in triplicate and stored at $5^{\circ} \mathrm{C}, 25^{\circ} \mathrm{C}$ and $35^{\circ} \mathrm{C}$. Samples, $1 \mathrm{ml}$ each, were removed at week 1, 2, 4, 6, 9 and 12 . The samples were placed in $1 \mathrm{ml}$ Eppendorf tubes and subjected to ultracentrifugation at $20,000 \mathrm{rpm}$ and $5{ }^{\circ} \mathrm{C}$ for 1 hour. The supernatant was removed and analyzed by UV-VIS spectrophotometry. The quantity of drug diffused out of vesicles was then calculated. Results represent average of three consistent observations.

\section{In-vitro drug release from vesicles}

The in-vitro release study was conducted using the dialysis tube method. An amount of microcapsule equivalent to $5 \mathrm{~g}$ of the drug was placed in a dialysis tube. This was suspended in a beaker containing $500 \mathrm{ml}$ of phosphate buffer saline $\mathrm{pH}$ 7.4) maintained at $37 \pm 1^{\circ} \mathrm{C}$ and subjected to magnetic stirring at $100 \mathrm{rpm}$. Aliquots of $2 \mathrm{ml}$ were withdrawn at $1 \mathrm{hr}$ interval and replaced with fresh medium equilibrated at $37^{\circ} \mathrm{C}$. The amount of drug in each aliquot was determined by UV-VIS spectrophotometry.

\section{Determination of Minimum Inhibitory Concentration of vesicles encapsulated fluoroquinolones}

The efficacy of the vesicular formulations was tested in parallel with the conventional drug using the broth microdilution technique. Inoculums were prepared at $0.5 \mathrm{Mc}$ Farlands standard $\left(1.0 \times 10^{4} \mathrm{cfu} / \mathrm{ml}\right)$ and 9 concentrations of each drug, ranging from $0.5 \mathrm{mcg} / \mathrm{ml}$ to $128 \mathrm{mcg} / \mathrm{ml}$, were tested.

\section{Statistical analysis}

Standard deviation and coefficient of variation were used to establish consistency of data at each level of the study. Paired sample $t$-test was performed for independent sample comparison while multi-group analysis was done with one-way analysis of variance (ANOVA) and significance determined at $95 \%$ confidence level using MINITAB 16 statistical package.

\section{Results and Discussion \\ Encapsulation efficiency}

Preliminary screening indicated that speed of rotation of 40 rpm, temperature of rehydration of $40^{\circ} \mathrm{C}$, time of rehydration of 4 hours and volume of rehydration of $4 \mathrm{ml}$ yield the maximum encapsulation of drugs in niosomes. The order of encapsulation efficiency was Ciprofloxacin $\geq$ norfloxacin $>$ levofloxacin $>$ gatifloxacin (Figure 1). The entrapment efficiencies for fluoroquinolones were maximized by adjusting the molar ratio of the drug to surfactant. The average encapsulation as percent of drug substrates were ciprofloxacin $(71.11 \pm 1.39 \%)$, gatifloxacin (19.11 $\pm 1.86 \%)$, levofloxacin $(34.23 \pm 1.86 \%)$ and norfloxacin $(70.09 \pm 1.64 \%)$.

Average particle size (D) of the niosomes ranged between 8 and $15 \mu \mathrm{m}(\mathrm{V}, 0.5)$ (Figure 2). The particles remained aggregated in spite of being shaken vigorously probably due to the high concentration of the dispersed phase (Figure 2). They were also highly polydisperse indicated by the high span values and wide bell-shaped distribution. The TEM images showed large aggregates of crystal-like (lamellar) structures in the Control and Ciprofloxacin samples (Figure $3 \mathrm{~A}$ and $3 \mathrm{~B}$ respectively). For gatifloxacin, levofloxacin and norfloxacin samples (Figures $3 C, 3 \mathrm{D}$ and $3 \mathrm{E}$ respectively), high population of vesicle-like (spherical) structures were observed.

The encapsulation efficiency $(\mathrm{EE})$ of the four fluoroquinolones appears to be polarity-dependent and decreased with increase in drug polarity. Thus, drug polarity has negative effect on molecular entrapment in niosomes, indicating that drug molecules were favorably located in the hydrophobic loci. The molecular structures of the fluoroquinolones are shown in Figure 4A-4D. The drug molecules have polar surfaces of 72.88 , $82.11,73.32$ and 72.88 and aqueous solubility of $1.1 \mathrm{mg} / \mathrm{L}$, $60.0 \mathrm{~g} / \mathrm{L}, 1.4 \mathrm{mg} / \mathrm{L}$ and $1.01 \mathrm{~g} / \mathrm{L}$ respectively for cipro-, gati-, levo- and norfloxacin [16,17]. Ciprofloxacin, the least polar drug, had the highest EE. Its molecule has a cyclopropyl group at N1 position (Figure 4A) [16], which gave the drug enhanced activity against gram negative organisms; however it also made the molecule less polar. Norfloxacin (same polar surface as ciprofloxacin) showed slightly lower EE than ciprofloxacin probably due to the presence of an ethyl group at the N1 position (Figure 4D). Ethyl group is an electron donor which makes the molecule more polar. Similarly, alkyl substitution of either the piperazine (gatifloxacin) or cyclopropyl ring (levofloxacin) improves polarity thereby reducing EE. Compared with ciprofloxacin, gatifloxacin has an additional methoxy side chain at C8 which serves as an electron donating group [17], enhance the polarity and reduced $\mathrm{EE}$. The order of encapsulation efficiency is CIP > NOR > GAT > LEV and is consistent with the 

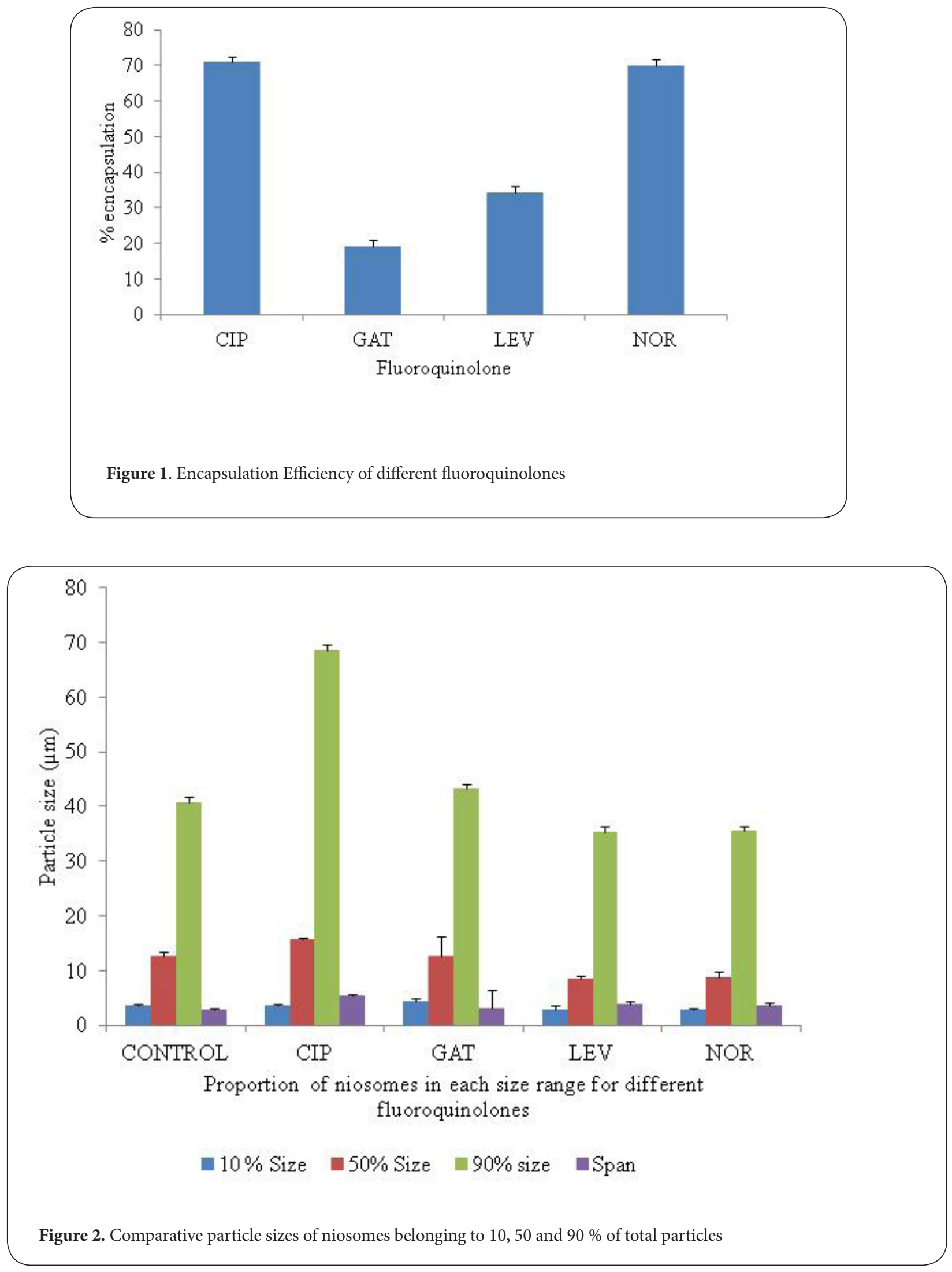


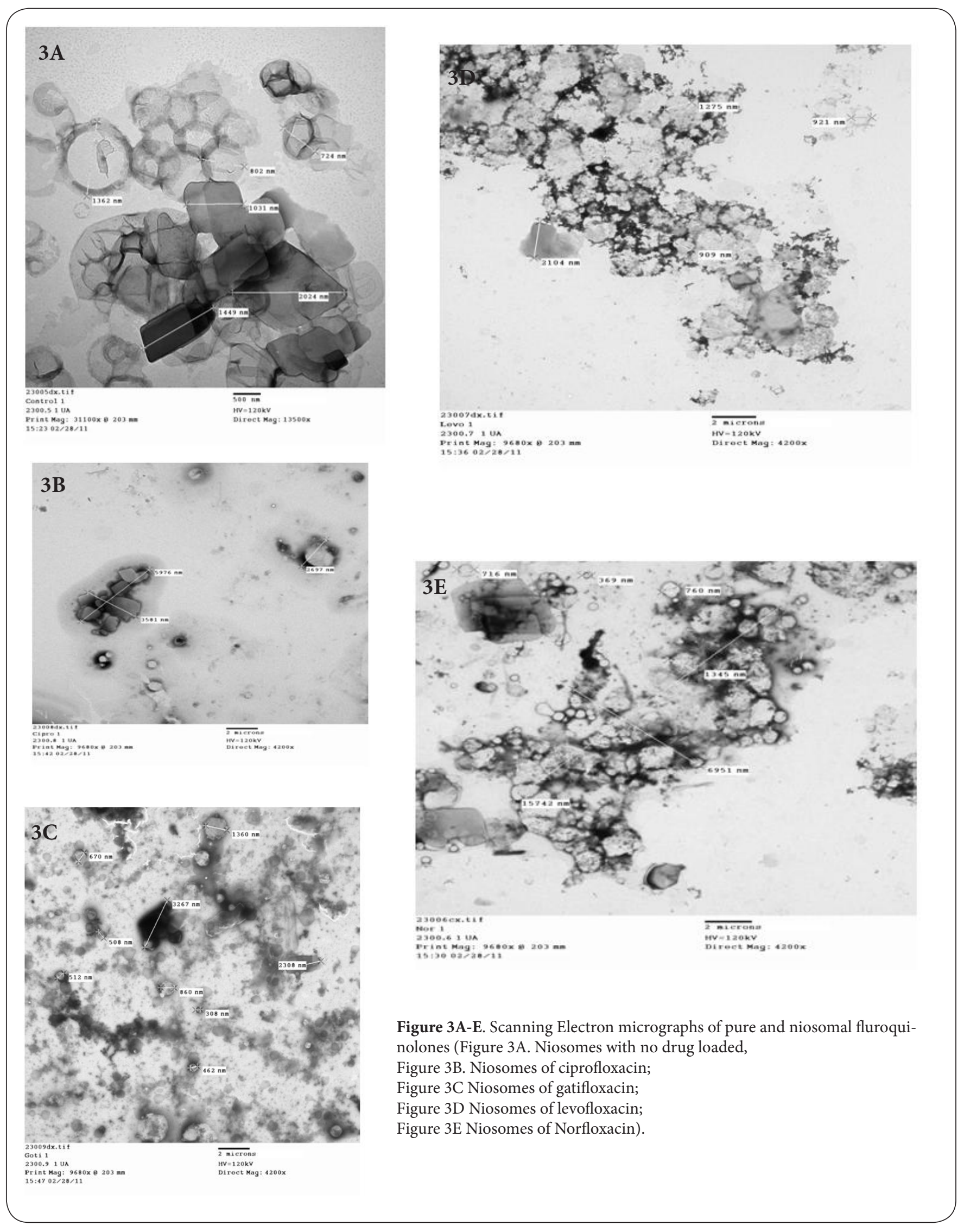



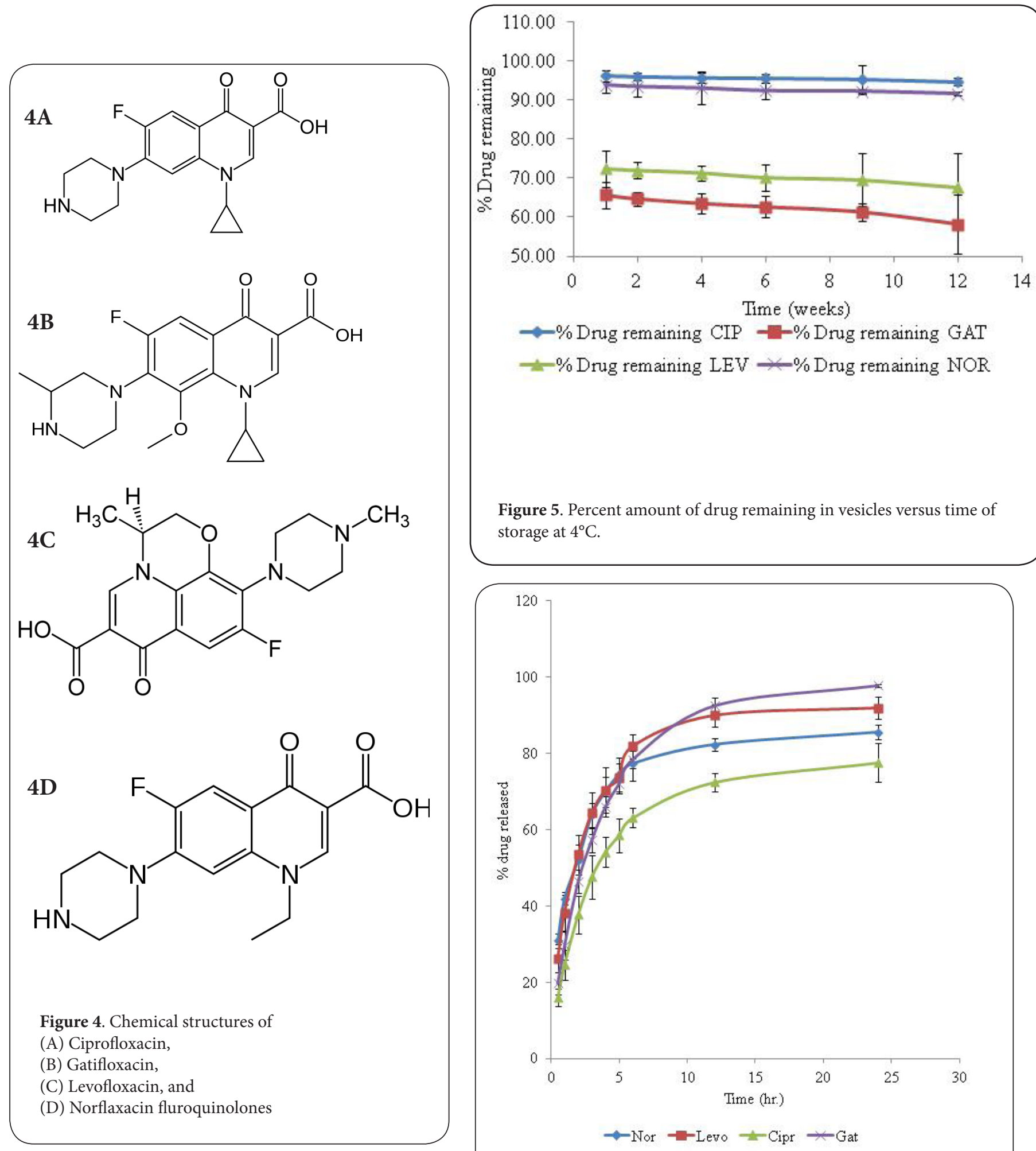

Figure 5. Percent amount of drug remaining in vesicles versus time of storage at $4^{\circ} \mathrm{C}$.

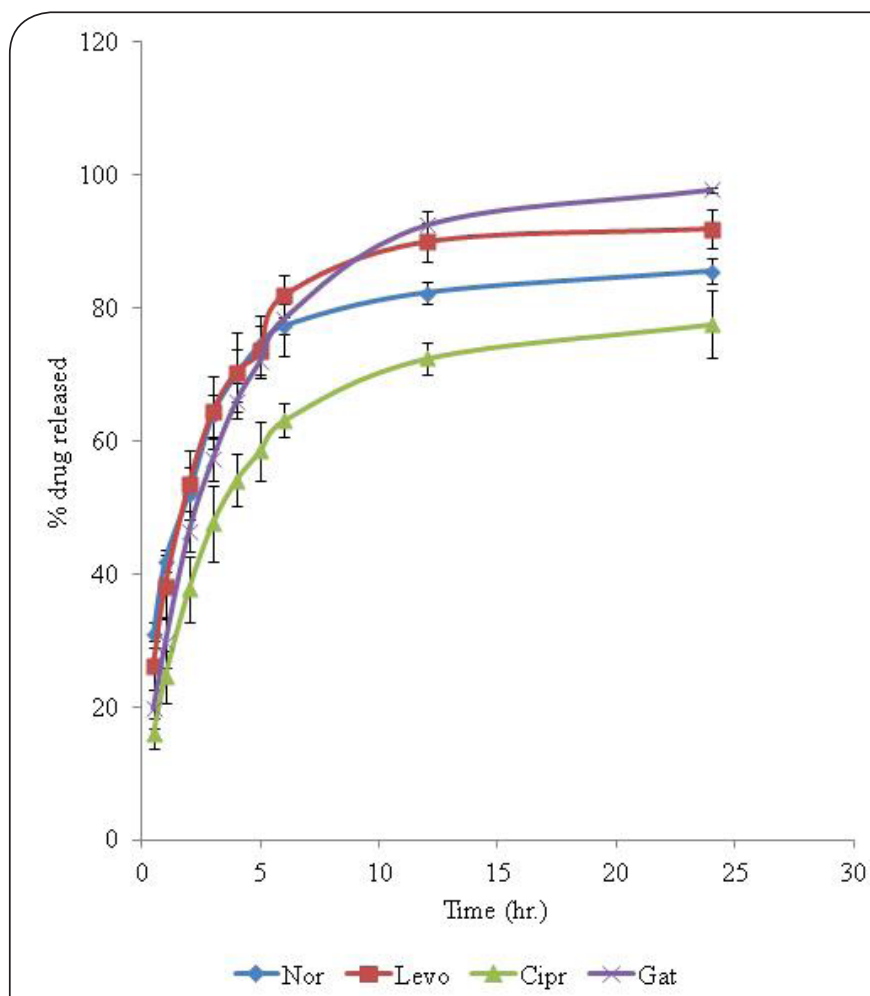

Figure 6. Dissolution profiles of noisome encapsulated fluoroquinolones. 
Adebayo et al. Journal of Pharmaceutical Technology \& Drug Research 2012,

http://www.hoajonline.com/journals/pdf/2050-120X-1-5.pdf

order of drug polarity of CIP $\approx \mathrm{NOR}<\mathrm{GAT}<\mathrm{LEV}$.

\section{Stability Study}

The three (3) month stability study indicated temperaturedependent stability. Typical profiles of niosomes stored at $5^{\circ} \mathrm{C}$ are shown in Figure 5. Amount of drug remaining after a storage period of three months were $94.7 \%, 91.6 \%, 67.7 \%$ and $58.2 \%$ respectively for cipro-, nor-, levo- and gatifloxacin respectively. Although encapsulation efficiency was higher for gati- than levofloxacin, the later retained the drug more effectively than gatifloxacin during storage. Effect of temperature on "noisome" stability can be ascribed to increase in fluidity of the bilayer with temperature which will promote thermodynamic instability and drug leakage $[18,19]$.

Arrhenius equation expresses the effect of temperature on decomposition and is employed in the calculation of the rate of loss of potency at storage temperatures from parameters obtained at elevated temperatures. The relationship between rate of decomposition and temperature is expressed as:

$$
\operatorname{Ln} K=\operatorname{Ln} A-\frac{E_{a}}{R} * \frac{1}{T}
$$

Where $E a=$ activation energy, i.e. the energy barrier to degradation; $A$ is the temperature-independent frequency factor; $R$ is the gas constant $\left(8.314 \mathrm{~J} \mathrm{~mol}^{-1} \mathrm{~K}^{-1}\right)$ and $T$ is the temperature in kelvins. Regression of $L n K$ against $1 / T$ produces a slope of $E a / R$ and an intercept of $\operatorname{Ln} A$. Parameters obtained for the fluoroquinolone niosomes are shown in Table 1. With two $\mathrm{K}$, obtained at two temperatures differing by $10^{\circ}$, an index $\left(Q_{10}\right)$ defined as the rate, $K_{2}$ at a temperature divided by $K_{1}$ at ten degree below that temperature can be obtained [20]. The $\mathrm{Q}_{10}$ values are shown in Table 2. $\mathrm{Q}_{10}$ can be used to estimate the shelf-life of the niosomes at a given temperature from its shelf-life at a known temperature by applying the equation:

$$
t_{90}\left(T_{2}\right)=\frac{t_{90}\left(T_{1}\right)}{Q_{10}^{\frac{(\Delta T)}{10}}}
$$

Where $t_{90}$ is the time for $10 \%$ loss in potency. At lower temperature between $5^{\circ} \mathrm{C}$ and $25^{\circ} \mathrm{C}$, rank order of $\mathrm{Q}_{10}$ (an indicator of niosomes sensitivity to temperature) was CIP $\leq$ GAT $\leq \mathrm{LEV}<$ NOR while at higher temperature, the rank order of sensitivity was GAT $\leq \mathrm{LEV} \leq \mathrm{NOR}<\mathrm{CIP}$. Generally, a $\mathrm{Q}_{10}$ of 1.7 (approximating 2) appears to be suitable for shelf-life prediction for the niosomes when stored at temperatures between $4^{\circ} \mathrm{C}$ and $37^{\circ} \mathrm{C}$.

\section{In-vitro Release}

The dissolution profiles of drugs from fluoroquinolone niosomes are shown in Figure 6. Amount of drug released in 6 hour (Q6h) and 24 hours (Q24h) were used to rank the fluoroquinolone niosomes. The order of magnitude of Q6h was Levo- $(81.8 \% \pm 2.9)>$ Gati- $(78.4 \pm 2.3)>$ Nor- $(77.3 \pm 4.4)$ $>$ Ciprofloxacin $(63.1 \pm 2.5)$ respectively. There was a slight difference in Q24h ranking: Gati- (97.8 \pm 0.4$)>$ Levo- (91.9 \pm 2.9) $>$ Nor- $(85.5 \pm 1.9)>$ Ciprofloxacin (77.5 \pm 5.0$)$. The in-vitro release patterns of all four fluoroquinolones are shown in Figure 6. Niosome encapsulation prevents "burst" release and this may mitigate against bacteria sensing of drugs and enable efficient fusogenic effect with the bacteria cells [12].

Data from dissolution test were fitted to different kinetic models to ascertain the mechanism that most appropriately describes the release process from niosomes. As shown in Table 3, first order kinetic model appears to be the most suitable for describing drug release from niosomes of fluoroquinolones. This implies that diffusion or release of the drug from the membrane bilayer is dependent on the amount of drug entrapped in the niosomes. The rate of release is therefore proportional to the amount of drug entrapped and follows exponential decay with time.

\section{MIC against drug-resistant bacteria strains}

The niosomal formulation of all four drugs produced at least two fold reductions of MIC's of Escherichia coli (Figure 7A) and Pseudomonas aeruginosa (Figure 7B), and at least a fourfold reduction in MIC's $(p<0.0001)$ of Staphylococcus aureus (Figure 7c). Niosomes' bilayer fluidity and fusogenic properties are two important factors in enhancing biological activity of the fluoroquinolones. Fusogenic properties allow for fusion of the niosome with the outer membrane of bacteria, thereby releasing its contents into the cell. Evidences suggest that multiresistance phenotype may be induced by bacterial exposure to polycationic peptides or inherited as a result of mutations affecting the sensor kinase ParS or the response regulator ParR. Recent observation suggests that ParRS mediates the adaptive response of $P$. aeruginosa to polycations such as polymyxin $\mathrm{B}$, colistin, and indolicidin at $\mathrm{Mg}^{2+}$ concentrations similar to those found in the human body (1 to $2 \mathrm{mM}$ ) [19]. Fernandez et al; [21] showed that activation of ParRS leads to up-regulation of the efflux system MexXY/OprM and down regulation of the porin OprD once a specific signal is detected in the bacterial environment.

Bilayer fluidity is of particular significance in gram-positive organisms which have the peptidoglycan barrier preventing direct contact with the niosomes. Report on liposomes with rigid bilayer structure showed very slow release of drug contents and low effectiveness against bacterial cells $[9,10]$. Thus niosomes with greater fluidity can release their contents at relatively faster rate on interaction with the external peptidoglycan barrier.

In all instances, the MIC of the niosomal formulations was lower than that of the conventional drugs. With respect to Pseudomonas aeruginosa, there was at least a two-fold decrease in MIC with niosomal ciprofloxacin, levofloxacin and norfloxacin, whilst gatifloxacin showed up to four-fold decrease in MIC 
Table 1. Parameters of the regression of LnK versus 1/T for fluoroquinolone niosomes

\begin{tabular}{cccccc}
\hline Drug & Slope, K & $\begin{array}{c}\text { Activation Energy, Ea } \\
\left(\text { Slope }^{\star} \mathbf{R}\right)\end{array}$ & $\begin{array}{c}\text { Intercept } \\
(\mathbf{L n A})\end{array}$ & $\begin{array}{c}\text { Frequency Factor } \\
(\mathbf{A})\end{array}$ & $\mathbf{R}^{2}$ \\
\hline NOR & 0.6863 & 5.7059 & -0.4415 & 0.6431 & 0.9641 \\
CIP & 0.5277 & 4.3873 & 0.2221 & 1.2487 & 0.8642 \\
LEV & 0.3948 & 3.2824 & -0.607 & 0.5450 & 0.9985 \\
GAT & 0.2665 & 2.2157 & -1.493 & 0.2247 & 0.9753 \\
\hline
\end{tabular}

$\mathrm{R} 2=$ regression coefficient, Activation energy, $\mathrm{Ea}=\mathrm{Slope}^{\star} \mathrm{R}$, Frequency factor, $\mathrm{A}=\mathrm{Ln}-1 \mathrm{~A}$

Table 2. Q10 for estimation of fluoroquinolone niosomes storage stability

\begin{tabular}{cccccc}
\hline Drug & $\begin{array}{c}\text { Storage } \\
\text { Temperature } \\
\text { (Kelvin) }\end{array}$ & $\mathbf{1 / T}$ & $\begin{array}{c}\mathbf{L n K} \\
\text { (slope })\end{array}$ & $\mathbf{K}$ & $\begin{array}{c}\mathbf{Q}_{\mathbf{1 0}} \\
\left(\mathbf{K}_{\mathrm{T}} / \mathbf{K}_{\mathbf{1}} /{ }_{10 \mathrm{~T}}\right)\end{array}$ \\
\hline CIP & 278 & 0.00323 & 0.8706 & 2.3883 & 1.1799 \\
& 298 & 0.00336 & 1.036 & 2.8180 & 2.4351 \\
& 310 & 0.0036 & 1.926 & 6.8621 & - \\
\hline GAT & 278 & 0.00323 & -1.202 & 0.3006 & 1.2129 \\
& 298 & 0.00336 & -1.009 & 0.3646 & 1.4050 \\
& 310 & 0.0036 & -0.669 & 0.5122 & - \\
\hline LEV & 278 & 0.00323 & -0.2035 & 0.8159 & 1.4456 \\
& 298 & 0.00336 & 0.165 & 1.1794 & 1.5235 \\
& 310 & 0.0036 & 0.586 & 1.7968 & - \\
\hline \multirow{2}{*}{ NOR } & 278 & 0.00323 & 0.1684 & 1.1834 & 2.4983 \\
& 298 & 0.00336 & 1.084 & 2.9565 & 1.579329 \\
& 310 & 0.0036 & 1.541 & 4.6693 & - \\
\hline
\end{tabular}

Table 3. Parameters of the kinetics equation describing the mechanisms of drug release from niosomes

\begin{tabular}{|c|c|c|c|}
\hline Kinetic Model & Slope & Intercept & Correlation Coefficien \\
\hline \multicolumn{4}{|l|}{ Ciprofloxacin } \\
\hline Zero order & 2.2251 & 36.057 & 0.6388 \\
\hline First order & 0.3168 & 1.2044 & 0.991 \\
\hline Higuchi & 7.5297 & 12.501 & 0.9754 \\
\hline Korsmeyer Peppa & 0.1563 & 1.5672 & 0.982 \\
\hline Hixon Crowell & 0.0569 & 3.248 & 0.5311 \\
\hline \multicolumn{4}{|l|}{ Gatifloxacin } \\
\hline Zero order & 2.8905 & 43.863 & 0.6595 \\
\hline First order & 0.3226 & 1.2874 & 0.9919 \\
\hline Higuchi & 9.6635 & 13.852 & 0.9828 \\
\hline Korsmeyer Peppa & 0.1646 & 1.6497 & 0.9731 \\
\hline Hixon Crowell & 0.0636 & 3.4696 & 0.5507 \\
\hline \multicolumn{4}{|l|}{ Norfloxacin } \\
\hline Zero order & 2.2738 & 51.43 & 0.5625 \\
\hline First order & 0.2542 & 0.4268 & 0.9903 \\
\hline Higuchi & 8.1097 & 25.283 & 0.954 \\
\hline Korsmeyer Peppa & 0.1218 & 1.7227 & 0.9901 \\
\hline Hixon Crowell & 0.0487 & 3.6709 & 0.4856 \\
\hline \multicolumn{4}{|l|}{ Levofloxacin } \\
\hline Zero order & 1.8467 & 52.544 & 0.54 \\
\hline First order & 0.2067 & 1.493 & 0.9909 \\
\hline Higuchi & 6.6752 & 30.864 & 0.9408 \\
\hline Korsmeyer Peppa & 0.1071 & 1.722 & 0.9901 \\
\hline Hixon Crowell & 0.0399 & 3.713 & 0.4797 \\
\hline
\end{tabular}




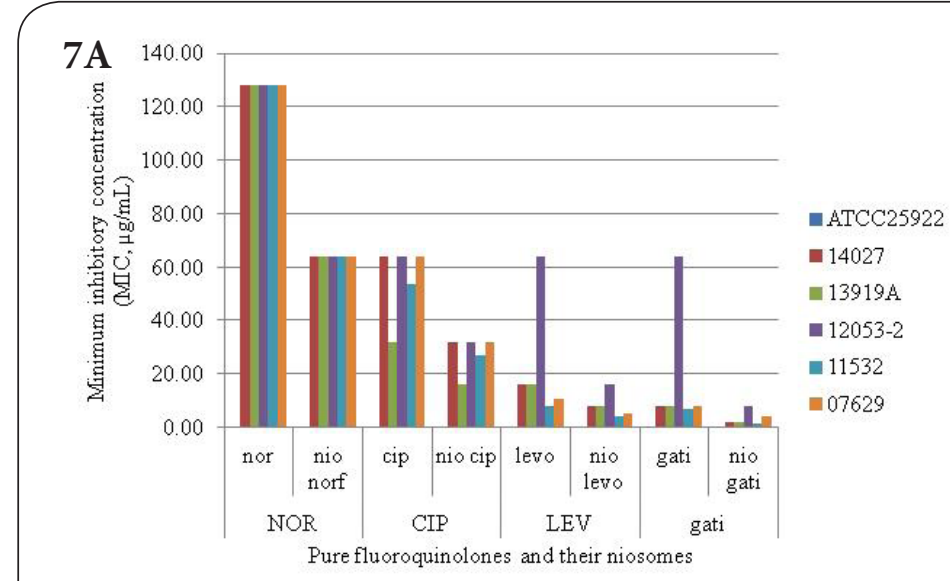

$7 \mathrm{~B}$

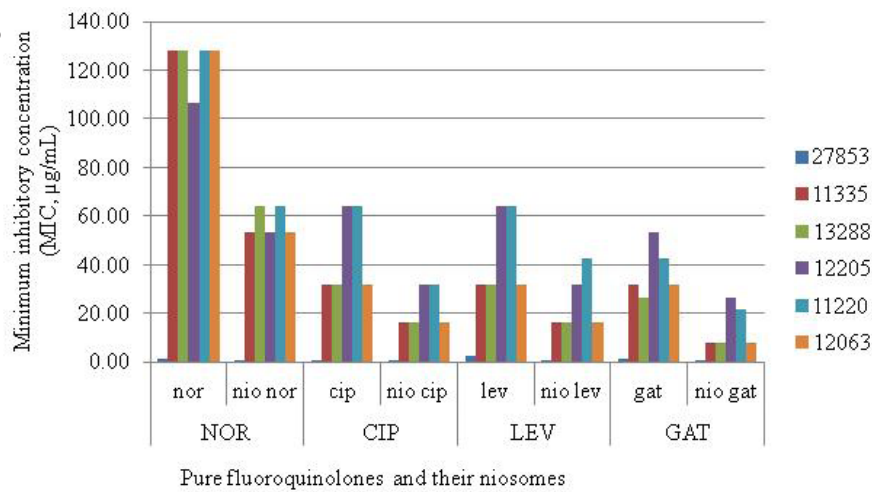

7C

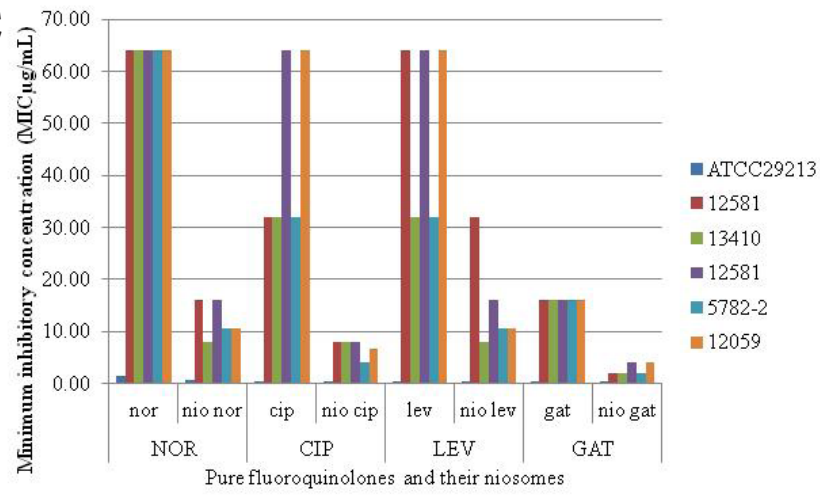

Figure 7A. Effect of niosomes encapsulation on MIC of fluoroquinolones against drug-resistant E. coli strains.

Figure 7B. Effect of niosomes encapsulation on MIC of fluoroquinolones against drug-resistant Ps. aeruginosa strains.

Figure 7C. Effect of niosomes encapsulation on MIC of fluoroquinolones against drug-resistant Staph. aureus strains. when compared to the conventional drugs. Escherichia coli showed similar results as the MICs of niosomal norfloxacin, ciprofloxacin and levofloxacin were at least two fold lower than conventional formulations. As with Pseudomona aeruginosa, gatifloxacin showed a fourfold reduction in MICs compared with the conventional drug. The experiments with Staphylococcus aureus showed a four-fold reduction in MICs for the niosomal formulations of all four drugs.

There are three methods by which fluoroquinolones may enter gram negative organisms, namely, the hydrophilic pathway through the porin channel (porin pathway), the pathway through the membrane bilayer matrix (hydrophobic pathway) and the self-promoted route used by cationic compounds $[12,18,19]$. The first two pathways seem to be influenced by properties of the drug such as hydrophobicity, molecular size and structure of the fluoroquinolone [12]. The results show an inherent ability of niosomes to deliver higher concentrations of the drugs to the bacterial cell. This may be due to the ability of niosome carrier to interact intimately with the outer membrane of the bacterial cell followed by noisome fusion with the cell with subsequent drug delivery via the hydrophobic or self-promoted pathway.

Various mechanisms of liposomal drug delivery to bacteria cells have been postulated that are applicable to niosomes, including reduced electrostatic repulsion of liposomal antibiotics from bacterial cell membrane and protection of the drug from bacterial enzymes $[12,13,22]$.

Muller et al; [11] showed the role played by a two-component signal transduction system (ParRS) in bacterial adaptation to at least four different classes of antibiotics (polymyxins, aminoglycosides, fluoroquinolones, and $\beta$-lactams) through three distinct resistance mechanisms: LPS modification, increased drug efflux, and a reduced porin pathway. It was concluded that multi-resistance phenotype may be induced by bacterial exposure to polycationic peptides or may be inherited as a result of mutations affecting the sensor kinase ParS or the response regulator ParR. Recent observation suggests that ParRS mediates the adaptive response of $P$. aeruginosa to polycations such as polymyxin $\mathrm{B}$, colistin, and indolicidin at $\mathrm{Mg}^{2+}$ concentrations similar to those found in the human body (1 to $2 \mathrm{mM}$ ) [18]. This demonstrates that activation of ParRS by the presence of specific signals in the bacterial environment leads to up- and down regulation of the efflux system MexXY/OprM and the porin OprD respectively. 
Fusions of niosome with outer membrane of organisms may elicit an increase in disorder and fluidity of biological membrane bilayer leading to greater membrane permeability. Thus there seems to be some promise in utilizing niosomal drug delivery system to curtail resistance patterns due to poor intracellular concentrations. The intrinsic resistance of gram negative bacteria is now believed to be a synergy of low outer membrane permeability coupled with efflux pump mechanisms such as that displayed by water filled channels porinF [23]. Since fluoroquinolones can cross the cytoplasmic membrane by simple diffusion, any condition which creates a concentration gradient towards bacterial cell outer membrane could improve drug permeation. Vesicles, apart from interacting with the outer membrane of bacteria, enable massive drug release close to bacterial surface creating a drug concentration gradient and facilitating faster rate of penetration than that of the free drug. Similar mechanism has been postulated for liposome from which drug is release close to the cell membrane or the peptidoglycan layer in gram-positive organisms [24]. This may be a more probable explanation for the enhanced activity in gram positive organisms as the presence of the peptidoglycan layer may limit interaction of the niosome with the outer cell membrane. Another factor that might have enhanced drug permeation is the small size of niosomal carriers which may support transport through porins as well as simple diffusion via aqueous channels. Further studies are required, however, for the definitive establishment of the mechanisms of niosomebacteria interaction.

\section{Conclusions}

Alteration of the trans-cellular transport patterns of fluoroquinolones is an important mechanism of bacterial resistance to this class of chemotherapeutic agents. In this study, we have demonstrated enhanced delivery of select fluoroquinolones to bacterial cells through noisomeencapsulation. Niosomes of tested fluoroquinolones produced significant reduction in MIC against multi-drug resistant strains of E. coli, Ps. aeruginose and Staph. aureus. Formulated niosomes showed temperature-dependent stability with the highest stability observed at $5^{\circ} \mathrm{C}$. In addition, drug release was by concentration-dependent, first-order kinetics which is desirable for rapid killing of bacteria cells.

\section{Competing interests}

The Authors declare that they have no competing interests.

\section{Author information}

${ }^{1}$ School of Pharmacy, Faculty of Medical Sciences, University of the West Indies, Faculty of Medical Sciences, St Augustine, Trinidad \& Tobago. ${ }^{3}$ College of Pharmacy, Sullivan University, Louisville, KY 40205, USA.

\section{Publication history}

Editor: Guangrong Zheng, University of

Arkansas for Medical Sciences, USA.

EIC: George Perry, University of Texas at San Antonio, USA.

Received: 27-Apr-2012 Revised: 18-May-2012 Accepted:

23-May-2012 Published: 6-June-2012

\section{References}

1. Paganoni R, Herzog C, Braunsteiner A, Hohl P: Fleroxacin: invitro activity worldwide against 20,807 clinical isolates and comparison to ciprofloxacin and norfloxacin. J Antimicrob Chemother 1988; 22 Suppl D;(3-17. I PubMed

2. Nix DE, Goodwin SD, Peloquin CA, Rotella DL, Schentag JJ: Antibiotic tissue penetration and its relevance: models of tissue penetration and their meaning. Antimicrob Agents Chemother 1991; 35;(10.);1947-52. I Article I PubMed Abstract | PubMed Full Text

3. Dalhoff $A$ (1989) A review of quinolone pharmacokinetics in Fernandes PB (Ed.) Telesymposium on Quinolones, J.R. Prous Science Publishers, Barcelona, Spain, 277-312.

4. Bergan T, Dalhoff A, Rohwedder R (1988) Pharmacokinetics of ciprofloxacin. Infection 16 (Suppl. 1) 3-13. | Article

5. Easmon CS, Crane JP: Uptake of ciprofloxacin by macrophages. J Clin Pathol 1985; 38;(4.);442-4. | Article | PubMed Abstract | PubMed Full Text

6. Easmon CS, Crane JP: Uptake of ciprofloxacin by human neutrophils. J Antimicrob Chemother 1985; 16;(1.);67-73. | Article I PubMed

7. Simoens S, Verhaegen J, van Bleyenbergh P, Peetermans WE, Decramer $\mathrm{M}$ : Consumption patterns and in vitro resistance of Streptococcus pneumoniae to fluoroquinolones. Antimicrob Agents Chemother 2011; 55;(6.);3051-3. I Article I PubMed Abstract | PubMed Full Text

8. Hvorup RN, Winnen B, Chang AB, Jiang Y, Zhou XF, Saier MH, Jr.: The multidrug/oligosaccharidyl-lipid/polysaccharide (MOP) exporter superfamily. Eur J Biochem 2003; 270;(5.);799-813. I Article I PubMed

9. Morita Y, Kataoka A, Shiota S, Mizushima T, Tsuchiya T: NorM of vibrio parahaemolyticus is an $\mathrm{Na(+)-driven} \mathrm{multidrug} \mathrm{efflux}$ pump. J Bacteriol 2000; 182;(23.);6694-7. I PubMed Abstract | PubMed Full Text

10. Poole K: Efflux-mediated antimicrobial resistance. J Antimicrob Chemother 2005; 56;(1.);20-51. I Article I PubMed

11. Muller C, Plesiat P, Jeannot K: A two-component regulatory system interconnects resistance to polymyxins, aminoglycosides, fluoroquinolones, and beta-lactams in Pseudomonas aeruginosa. Antimicrob Agents Chemother 2011; 55;(3.);1211-21. | Article | PubMed Abstract | PubMed Full Text

12. Wong JP, Yang H, Blasetti KL, Schnell G, Conley J, Schofield $\mathrm{LN}$ : Liposome delivery of ciprofloxacin against intracellular Francisella tularensis infection. J Control Release 2003; 92;(3.);265-73. | Article I PubMed | Free Full Text

13. Furneri PM, Fresta M, Puglisi G, Tempera G: Ofloxacin-loaded liposomes: in vitro activity and drug accumulation in bacteria. Antimicrob Agents Chemother 2000; 44;(9.);2458-64. I Article I PubMed Abstract | PubMed Full Text

14. Uchegbu, IF, Florence, AT (1995) Nonionic surfactant vesicles (niosomes): physical and pharmaceutical chemistry. Adv. Colloid Interface Sci.58: 1 - 55. 
15. Florence AT, Attwood D: Physicochmical principles of pharmacy. $4^{\text {th }}$ Ed. p215.2006. | Book

16. The Drug Bank Database Accesses May 21 at: www. http:// www.drugbank.ca/drugs

17. Beringer P, DerMardersonian A, Felton L, Gelone S, Gennaro AR et al.: Remington - The science and practice of pharmacy. 21 $1^{\text {st }}$ Ed. p1656. 2006.

18. Desiderio JV, Campbell SG: Intraphagocytic killing of Salmonella typhimurium by liposome-encapsulated cephalothin. J Infect Dis 1983; 148;(3.);563-70. | Article | PubMed

19. Desiderio JV, Campbell SG: Liposome-encapsulated cephalothin in the treatment of experimental murine salmonellosis. J Reticuloendothel Soc 1983; 34;(4.);279-87. | PubMed

20. Allen LV, Popovich N, Ansel H: Ansel's pharmaceutical dosage forms and drug delivery systems $9^{\text {th }}$ ed. p90-142. 2011.

21. Fernandez L, Gooderham WJ, Bains M, McPhee JB, Wiegand I, Hancock RE: Adaptive resistance to the "last hope" antibiotics polymyxin B and colistin in Pseudomonas aeruginosa is mediated by the novel two-component regulatory system ParR-ParS. Antimicrob Agents Chemother 2010; 54;(8.);337282. | Article | PubMed Abstract | PubMed Full Text

22. Mugabe C, Halwani M, Azghani AO, Lafrenie RM, Omri A: Mechanism of enhanced activity of liposome-entrapped aminoglycosides against resistant strains of Pseudomonas aeruginosa. Antimicrob Agents Chemother 2006; 50;(6.);201622. | Article | PubMed Abstract | PubMed Full Text

23. Woodruff WA, Parr TR, Jr., Hancock W, Hanne LF, Nicas TI, Iglewski BH: Expression in Escerichia coli and function in pseudomonas aeruginosa outer membrane porin protein $F$. Bacteriol. 1986; 167:473-479. | Article | PubMed Pdf

24. New RRC, Black CDV, Parker RJ, Puri A, Scherphof GL: Liposomes in biological sytems In R.R.C. New (Ed.) Liposomes: a practical approach. I.R.L. Press-Oxford University Press, New York, N.Y. 1990; p221-252.

\section{Citation:}

Satish J, Amusa A S and Pillai G: In Vitro Activities of Fluoroquinolones Entrapped in Non-ionic Surfactant Vesicles against Ciprofloxacin-Resistant Bacteria Strains. journal of Pharmaceutical Technology and Drug Research 2012, 1:5.

http://dx.doi.org/10.7243/2050-120X-1-5 